\title{
Topical, Biological and Clinical Challenges in the Management of Patients with Acne Vulgaris
}

Anwar Al-Hammadi, ${ }^{1}$ Abla Al-Ismaily, ${ }^{2}$ Sameer Al-Ali, ${ }^{3}$ Rajesh Ramadurai, ${ }^{4}$ Rishi Jain, ${ }^{4}$ Lynn McKinley-Grant, ${ }^{5}$ "Tariq I. Mughal ${ }^{6}$

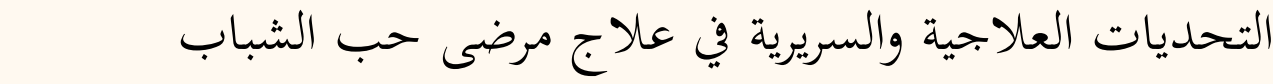

$$
\text { أنور الحمداني، عبلة الإسماعلية، سمير العلي، راجيش رامادوراي، ريشى جين، لين ماكنلي جرانت، طارق موجال }
$$

ABSTRACT: Acne vulgaris is one of the most common chronic inflammatory skin disorders among adolescents and young adults. It is associated with substantial morbidity and, rarely, with mortality. The exact worldwide incidence and prevalence are currently unknown. Current challenges involve improving understanding of the underlying pathophysiology of acne vulgaris and developing a practical treatment consensus. Expert panel discussions were held in 2013 and 2014 among a group of scientists and clinicians from the Omani and United Arab Emirate Dermatology Societies to ascertain the current optimal management of acne vulgaris, identify clinically relevant end-points and construct suitable methodology for future clinical trial designs. This article reviews the discussions of these sessions and recent literature on this topic.

Keywords: Acne Vulgaris; Molecular Biology; Diagnosis; Therapeutics; Benzoyl Peroxide; Retinoids; Isotretinoin; Antibiotics.

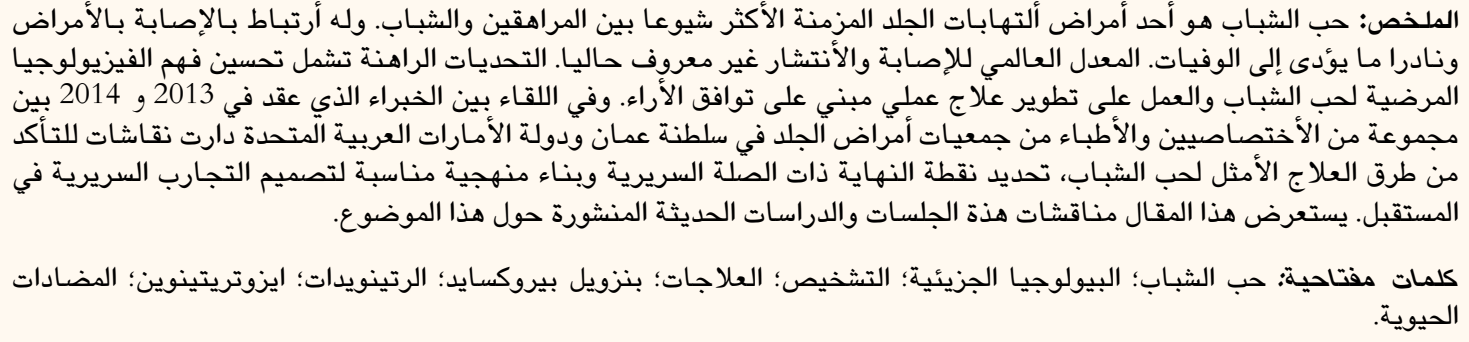

A CNE VULGARIS IS A COMMON CHRONIC inflammatory disorder of the pilosebaceous unit among adolescents and young adults. ${ }^{1}$ It is associated with substantial morbidity and sometimes mortality due to associated disorders. ${ }^{2}$ The term acne was introduced by the Greek philosopher Celsus in the second century C.E. to describe the presence of pustules/papules on the skin, although the ancient Roman physician Pliny had previously used the word 'varus' to describe similar pustules. ${ }^{3}$ The condition is part of a heterogeneous group of skin disorders, the precise aetiology of which is unknown; however, several potential aggravating factors have been identified. ${ }^{4}$ The main feature is a chronic process leading to excessive sebum production (seborrhoea), altered keratinisation and bacterial colonisation by Propionibacterium acnes within the pilosebaceous units or hair follicles. ${ }^{4}$ The natural history is that of a non-inflammatory process, resulting in open and closed comedones and widespread inflammatory lesions including papules, pustules [Figure 1], nodules, cysts and scarring. ${ }^{1}$ These lesions can evolve rapidly in some patients and are likely androgen-induced. ${ }^{2}$

The current challenge in treating acne vulgaris is improving the understanding of its precise underlying cellular and molecular biology, identifying any potential candidate trigger factors and developing treatment guidelines within a regional and demographic context. The latter concept is of particular interest in view of several recent reports suggestive of diverse causal factors, such as seasonal variations, unique dietary and ethnic factors and comorbidities. ${ }^{5,6}$ Other factors which need to be addressed include the precise methods and timing of treatment and which strategies 


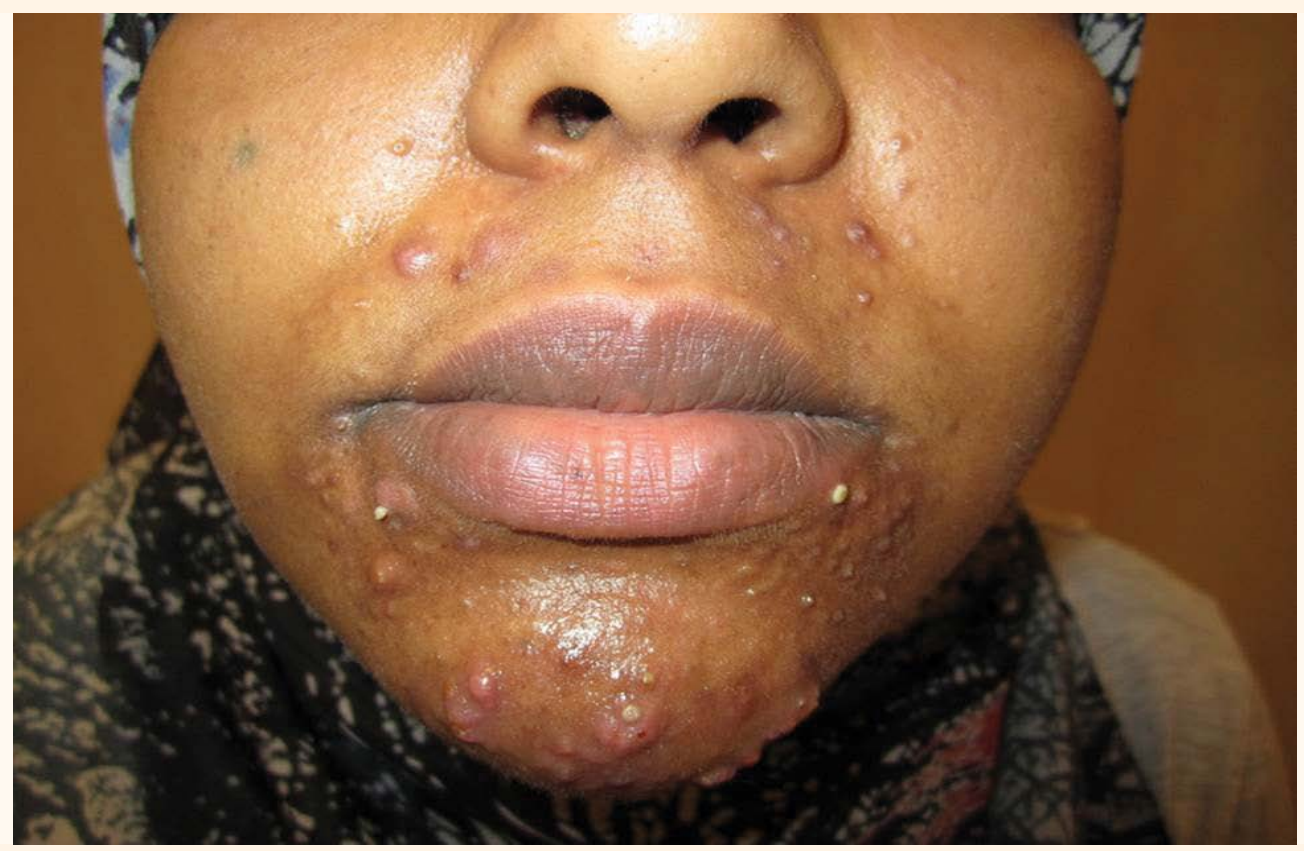

Figure 1: Photograph of a young female patient with moderate to severe acne vulgaris with pustular formation.

yield optimal long- and short-term clinical outcomes. Little, if any, high-quality evidence exists to support the effectiveness and safety of many existing therapies, particularly topical therapies. Evidently, new research is urgently required to better understand the biology and treatment of acne. Recent efforts have also identified potential genetic and molecular abnormalities; concepts of how best to integrate such advances into treatment algorithms will also therefore need to be addressed. ${ }^{7,8}$ In addition, new research is needed to assess the comparative therapeutic effectiveness and safety of the many available medications for acne treatment, determine the best preventive strategies and investigate the natural history, subtypes and triggers of this condition.

This review seeks to clarify some of these challenges and the natural history of treatment in order to help improve clinical outcomes for patients with acne vulgaris. An international panel of scientific and clinical experts was formed under the aegis of the United Arab Emirates (UAE) and Omani Dermatology Societies to review current knowledge regarding the biology and diagnosis of acne vulgaris and novel therapeutic approaches. An independent panel convened on 11 October 2013 in Dubai, UAE, 12 October 2013 in Muscat, Oman, and on 16 September 2014 in Dubai. This review reflects the results of these discussions as well as information collected from literatures searches on the MEDLINE, Google Scholar and Cochrane Library databases using the terms acne and acne vulgaris.

\section{Epidemiology}

The precise worldwide incidence and prevalence of acne vulgaris is currently unknown; this is unusual given that it is considered a common disease globally. Hospital-based dermatology registries in the USA suggest that approximately 40-50 million people and $80 \%$ of adolescents and young adults are affected by this condition. ${ }^{9}$ In the UK, recent estimates suggest that acne accounts for more than 3.5 million annual visits to general practioners. ${ }^{10}$ A Kuwaiti study assessing over 3,700 patients with skin disorders indicated that approximately $75 \%$ of the study cohort had non-infectious disorders compared to $25 \%$ with infection-related skin ailments; the researchers found that acne was the second most common skin disorder (9.41\%) after atopic dermatitis (11.07\%). ${ }^{11}$ A Saudi Arabian study revealed similar findings in a cohort of 3,051 patients with skin disorders. ${ }^{12}$ Further research from Saudi Arabia confirmed that acne vulgaris was a common dermatological condition, accounting for $20-30 \%$ of all skin disorders. ${ }^{13}$ In the UAE, acne vulgaris anecdotally comprises $30 \%$ of all chronic skin conditions; other research has indicated that this condition is the cause of $9 \%$ of all dermatology outpatient visits. ${ }^{14-16}$

Acne vulgaris appears to affect more pubescent boys than girls; in contrast, when the disorder affects adults, more women than men appear to be affected. ${ }^{4}$ A Western study among Arab Americans reported a peak incidence of acne vulgaris occurring 
in adolescents at puberty. ${ }^{17}$ An Iranian communitybased study involving individuals aged $12-20$ years old reported an overall acne prevalence of $93.2 \%$; the prevalence was higher in females, with a female-tomale ratio of 1:0.4. ${ }^{18}$ The researchers speculated that this ratio perhaps reflected gender-based perceptions of overall body image, with females more likely to seek dermatological assessment than adolescent boys. ${ }^{18}$ Acne can have profound psychosocial effects as well as result in permanent skin scarring; ${ }^{19}$ these can act as a motivation for acne patients to seek medical attention. A recent Syrian study found that the prevalence of acne increased with body mass index..$^{20}$

\section{Pathophysiology}

The precise pathogenesis of acne vulgaris has remained enigmatic, although overproduction of sebum, altered keratinisation and bacterial colonisation by P. acnes within the pilosebaceous units are generally agreed upon as causal factors. ${ }^{4}$ The significant role of androgens is also recognised. ${ }^{2}$ The Gram-positive bacterium $P$. acnes, which is part of the normal skin microbiome, is present in the pilosebaceous units and uses lipid-rich sebum as a nutrient source; its growth is therefore increased in the presence of acne-associated excessive sebum production. ${ }^{21}$ Lipid-rich sebum is hydrophobic in nature and it facilitates lubrication and protection of the skin while $P$. acnes hydrolyses triglycerides in the sebum, causing the release of free fatty acids which increase the chance of bacterial adherence. The potential association of Demodex mites and acne vulgaris has been speculated upon, but definitive evidence remains elusive. ${ }^{9}$

\section{INFLAMMATORY FACTORS}

Agak et al. suggested that $P$. acnes plays an important role in eliciting an inflammatory response by activating inflammasomes, which in turn results in the production of interleukin (IL)-1 $\beta$ and other inflammatory cytokines. ${ }^{22}$ P. acnes was a potent inducer of $\mathrm{T}$ helper (Th) 17 and Th1; however, it did not induce Th2 responses in human peripheral blood mononuclear cells. In addition, $P$. acnes was found to stimulate the expression of key Th17-related genes, including $I L-17 A$, retinoid-related orphan receptor $(R O R) \alpha, R O R C, I L-17 A$ receptor and $I L-17 C$ receptor, as well as trigger IL-17 secretion from cluster of differentiation (CD) $4^{+}$cells, but not from $\mathrm{CD}^{+} \mathrm{T}$ cells.22 Agak et al. also noted that the combination of IL-1 $\beta$, IL- 6 and transforming growth factor- $\beta$ neutralising antibodies completely inhibited $P$. acnesinduced IL-17 production. ${ }^{22}$ This is of considerable interest since IL-17-expressing cells were present in skin biopsies from patients with acne vulgaris but not in healthy controls. Furthermore, it was observed that all-trans-retinoic acid and 1,25-dihydroxyvitamin $\mathrm{D}_{3}$ inhibits $P$. acnes-induced Th17 differentiation. ${ }^{22}$ Collectively, these observations support the notion of using both retinoids and 1,25-dihydroxyvitamin $\mathrm{D}_{3}$ in inhibiting the above inflammatory cascades. Kistowska et al. also confirmed the idea that $P$. acnes activates inflammasomes, resulting in the production of IL-1 $\beta .^{23}$ The investigators were able to decipher the underlying mechanisms which contribute to the inflammatory lesions in acne by demonstrating that IL- $1 \beta$ messenger ribonucleic acid and the active processed form of IL-1 $\beta$ are abundant in these lesions in a murine model. They hypothesised that $P$. acnes activates the monocytemacrophage nucleotide-binding domain leucine-rich repeat family pyrin domain containing-3 (NLRP3) inflammasome and activates a cascade reaction involving IL-1 $\beta$ processing, lysosomal destabilisation, reactive oxygen species and cellular potassium efflux. ${ }^{23}$ If confirmed independently, the NLRP3 inflammasome and IL-1 $\beta$ appear to be candidate therapeutic targets for acne treatment.

\section{GENOMIC LANDSCAPE}

A recent genomic analysis of over 1,000 Chinese patients with severe acne vulgaris revealed two new genetic factors that could potentially play a role in the pathogenesis of this condition. ${ }^{7}$ The study found that two genetic loci-11p11.2 (for the damage-specific DNA binding protein 2 gene) and 1q24.2 (for the selectin $L$ gene)-were involved in androgen metabolism, inflammation processes and scar formation. ${ }^{7}$ Yaykasli et al. recently demonstrated the importance of extracellular matrix remodelling, which is regulated by matrix metalloproteinases and tissue inhibitors of metalloproteins (TIMP), in the pathogenesis of acne vulgaris. ${ }^{24}$ The investigators analysed polymorphisms in 85 patients with acne vulgaris and noted that the TIMP-2 (-418 G>C) genotype was twice as prevalent in the study cohort in comparison to normal controls. ${ }^{24}$

\section{FUTURE RESEARCH}

Recently, there has been interest expressed in other molecular abnormalities, such as Toll-like receptor 2 (TLR2) activation and comedogenesis. Selway et al. observed the expression of TLR2 in basal and infundibular keratinocytes and sebaceous glands and determined that TLR2 activation led to the release of IL- $1 \alpha$ from primary human keratinocytes. ${ }^{8}$ In addition, Selway et al. suggested that the release of IL-1 $\alpha$ from infundibular keratinocytes in response to $P$. acnes- 


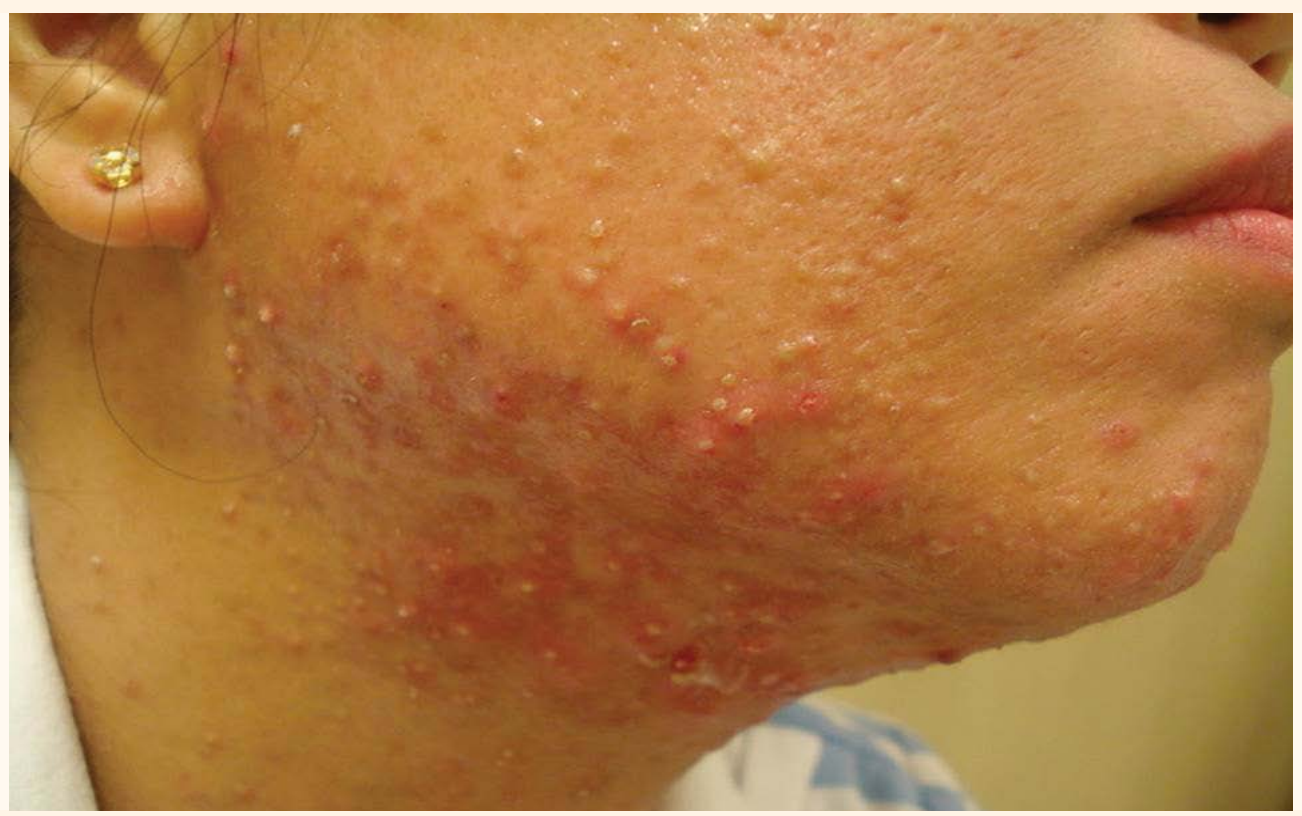

Figure 2: Photograph of a young female patient with moderate acne vulgaris.

mediated TLR2 activation could be the initiating steps in comedogenesis and acne formation. ${ }^{8}$ Additionally, IL-1 $\alpha$ may cause sebaceous hypercornification, a feature of acne. ${ }^{8}$

Increased fibroblast growth factor receptor-2 (FGFR2) signalling has been proposed in the pathogenesis of acne and related disorders, following initial observations in patients with Apert syndrome and acneiform nevus with a gain-of-function mutation in the FGFR2 gene. ${ }^{25,26}$ Furthermore, several studies have provided in vitro evidence of many anti-acne agents, including benzoyl peroxide (BPO), antiandrogens and retinoids, attenuating FGFR2 signal transduction in murine models. ${ }^{27,28}$ Collectively, these inflammatory, genetic and molecular findings are of considerable interest and may pave the way to the identification of candidate pathways and targets for acne vulgaris treatment (e.g. NLRP3 inflammasomes and IL-1ß) in future clinical trials.

\section{Clinical Features}

Most acne patients present with localised lesions on the face, neck [Figure 2] and truncal areas. However, acne vulgaris can affect all areas of the body except the palms of the hands and soles of the feet, as these regions do not have sebaceous glands. Even ocular areas can be involved; the meibomian glands (also known as tarsal glands) are sebaceous and produce the lipid layer of tears. Additionally, with severe acne vulgaris, in particular the nodulocystic type, pilosebaceous units on the eyelids may sometimes produce ocular symptoms. ${ }^{4,29}$ A range of diverse factors have been found to clinically impact acne vulgaris, including stress levels, diet and even seasonal variation; these factors might be affected by prevailing regional geographical and cultural elements and therefore merit further study and validation., ${ }^{5,6}$ Additionally, there appears to be some causal evidence supporting a link between acne and hyperglycaemic diets, certain dairy products and refined sugars. ${ }^{5}$

There is little doubt that acne vulgaris results in significant morbidity, in particular with regards to its impact on quality of life (QOL). However, this condition can also result in mortality by affecting self-esteem and increasing the risk of suicide, particularly in cases of severe acne. ${ }^{30}$ Severe acne appears to be more prevalent in older age and among females, Caucasians and those with a higher socioeconomic status. ${ }^{4}$ Studies from Iran and Saudi Arabia have confirmed the symptom burden associated with severe acne vulgaris. ${ }^{19,31,32}$ Research has demonstrated an association between severe acne and several other conditions, ranging from sinopulmonary to gastrointestinal and psychological comorbidities; the latter includes depression, insomnia and attention deficit and hyperactivity disorders. ${ }^{33}$ Scarring is a serious complication of acne vulgaris and occurs commonly despite the high availability of acne treatment options. The scars occur due to skin damage during the healing process. Acne scars are often atrophic and are sometimes accompanied by hyperpigmentation; they can therefore have considerable psychological impact, often affecting QOL. ${ }^{34}$ These observations indicate the importance 


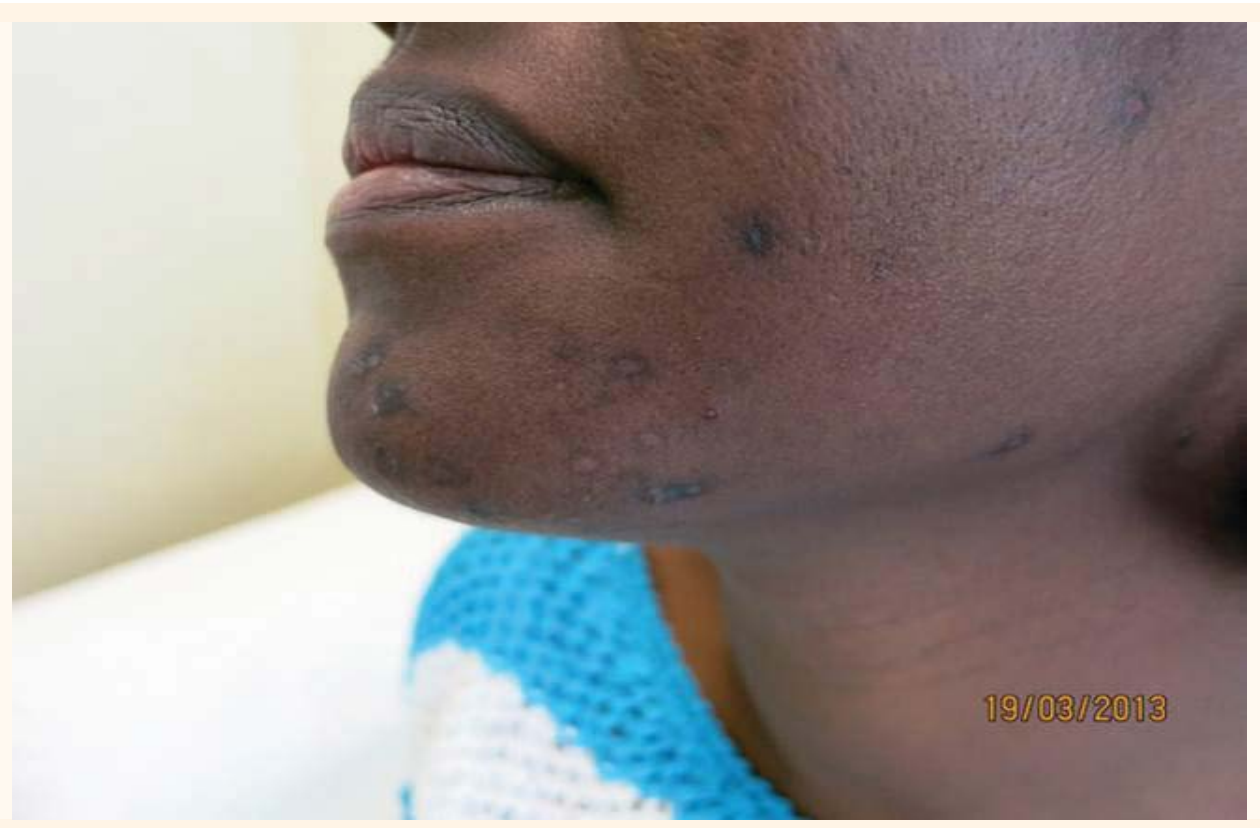

Figure 3: Photograph of a young female patient with post-acne vulgaris hyperpigmentation and scarring.

of multidisciplinary assessment for acne patients, preferably by a team which includes dermatologists, psychologists and psychiatrists.

\section{Clinical Management}

In the absence of well-defined aetiological factors, the principle objective for optimal clinical management of acne vulgaris is to identify potential precipitating and/or aggravating factors and to prevent significant associated morbidities. ${ }^{2}$ Additionally, it is important to prevent new acneiform lesions and associated scarring

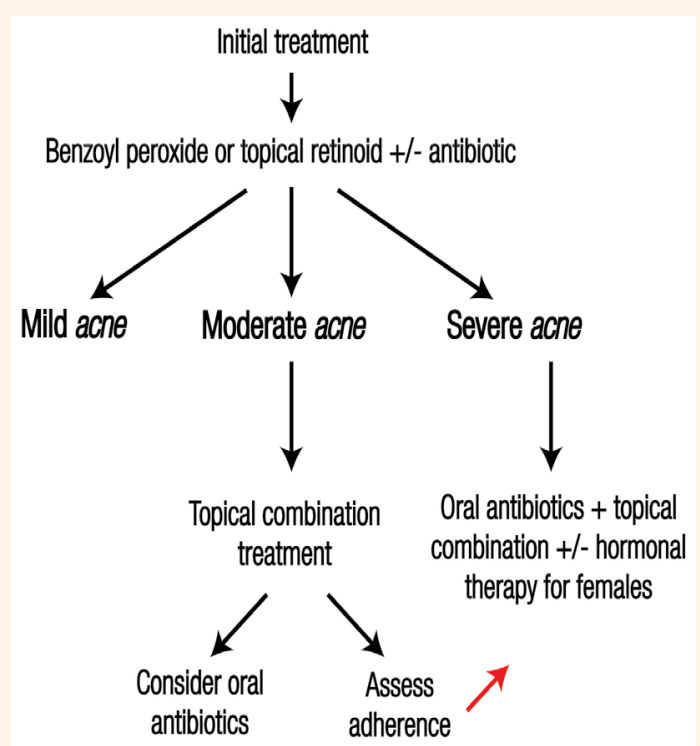

Figure 4: Flowchart detailing a potential treatment algorithm for patients with mild, moderate or severe forms of acne vulgaris. and hyperpigmentation [Figure 3]. Most experts advocate the use of a stepwise treatment algorithm in accordance with the severity of the disorder, typically combining non-pharmacological and pharmacological agents concomitantly with counselling and support. ${ }^{9,10}$ Topical agents, including BPO, retinoids, azelaic acid and antibiotics are used to control mild to moderate acne. Systemic therapy, such as oral antibiotics and oral retinoids, tend to be reserved for patients with severe acne; they are often combined with BPO or topical retinoids such as adapalene and tretinoin. Although there are a lack of randomised trials comparing topical versus oral treatments, several consensusbased recommendations and treatment algorithms are available. ${ }^{1}$ Figure 4 depicts a potential treatment flowchart for adult patients with mild, moderate or severe acne.

\section{TOPICAL THERAPIES}

For topical therapy, most specialists tend to use BPO or adapalene, a third-generation topical retinoid, or a combination of the two for the treatment of mild to moderate acne. First introduced in 1934 for the treatment of papulopustular acne, BPO appears to have diverse mechanisms of action, including antibacterial mechanisms by virtue of its oxidative effect and sebostatic and comedolytic properties., ${ }^{2,4}$ $\mathrm{BPO}$ is effective, rapid and substantially reduces $P$. acnes colonies while also reducing the risk of resistance when used in combination with topical antibiotics. ${ }^{35}$ Adapalene has been in clinical use for over two decades; research has confirmed its efficacy 
and safety, both as a monotherapy and when combined with topical antibiotics. ${ }^{36}$ Both tretinion and adapalene are anti-inflammatory agents; however, adapalene works by inhibiting keratinocyte differentiation and comedone formation. Topical antibiotics are known to inhibit $P$. acnes and reduce inflammation. ${ }^{4}$ Azelaic acid appears to have antimicrobial and anticomedonal properties. ${ }^{37}$ In addition, it can cause hypopigmentation which might help patients to counteract any post-inflammatory hyperpigmentation. Other topical agents include salicylic acid, which is also an exfoliant, and dapsone. There is some evidence supporting the use of combinations of topical treatments with different mechanisms of action. ${ }^{37-39}$

Both BPO and adapalene are available in a variety of strengths. Although the efficacy is generally similar, higher concentrations are often associated with increased side-effects, such as skin peeling and irritation. ${ }^{40}$ A fixed-dose combination of $0.1 \%$ adapalene and $2.5 \% \mathrm{BPO}$ is also available. ${ }^{36}$ In addition to topical BPO and adapalene, the treatment guidelines of the American Academy of Dermatology (AAD) also recommend topical antibacterials, such as erythromycin and clindamycin. ${ }^{41}$ Evidence from several randomised studies supports the use of a combination of topical antibacterial and BPO therapy. ${ }^{37-39}$ In a double-blind controlled study involving 378 patients, Dréno et al. demonstrated the clinical benefit of combining adaplene or BPO with lymecycline in comparison to treatment with $\mathrm{BPO}$ and a placebo. ${ }^{37}$ A Turkish clinical trial among young adults with mild to moderate facial acne vulgaris found that combination 5\% BPO lotion was significantly more effective in the reduction of inflammatory lesions compared with $1 \%$ nadifloxacin cream alone. ${ }^{38}$ Furthermore, it has been shown that combination therapy is also more effective in preventing relapse compared to monotherapy. ${ }^{39}$ Currently, most specialists advocate the use of $0.02-0.05 \%$ topical retinoids on all affected areas for mild to moderate forms of acne. ${ }^{42}$

\section{ORAL THERAPIES}

Oral retinoids, in particular isotretinoin, reduce the size of the sebaceous glands and reduce sebum production which helps to normalise follicular epithelial desquamation; topical retinoids also appear to have these characteristics, although to a lesser degree. ${ }^{4}$ According to the current AAD guidelines, both topical and oral formulations have a strong evidence-based recommendation (category IA). ${ }^{41}$ In general, most patients appear to achieve longer-term positive responses with both formulations. ${ }^{40}$ Oral retinoids are generally reserved for more severe forms of acne or for patients who are resistant/refractory to conventional therapy, regardless of severity. While side-effects-including skin irritation and peelingare common, these effects are usually mild and easily managed. ${ }^{43}$ Retinoids are rarely associated with other potentially serious adverse side-effects, such as psychiatric issues and, in particular, depressive illnesses. ${ }^{4,43}$ The association between psychiatric issues and retinoids is challenging to address since such side-effects are often already present among patients with acne vulgaris, especially those with moderate or severe forms. ${ }^{30-32}$ A study from the UAE found that oral isotretinoin was effective in improving psychiatric comorbidities and body image among adolescents and young adults with severe acne. ${ }^{44}$ Another study noted that certain patients undergoing oral isotretinoin therapy sometimes demonstrated abnormalities in liver function tests and serum lipids, especially lowdensity lipoproteins and triglycerides; however, this was generally reversible upon discontinuation of the therapy. ${ }^{45}$

Oral antibiotics, such as tetracyclines, erythromycin and clindamycin, are often utilised as part of a combination regimen for patients with severe acne, particularly in the presence of inflammatory lesions. ${ }^{46-48}$ Antimicrobials should be discontinued once the inflammatory lesions abate and other treatments, such as topical agents, should be used as maintenance therapy thereafter. While antibiotics are generally well-tolerated, they are occasionally associated with severe adverse events. ${ }^{40}$ There appears to be no important difference in the efficacy of the choice or dose of antibiotics; the decision is often based on patient preference, cost and side-effect profile. $^{44,45}$ However, there is considerable concern regarding antibiotic resistance; as such, their use for extended periods should be avoided. ${ }^{49,50}$ Concomitant $\mathrm{BPO}$ use helps to reduce the risk of resistance, possibly by eliminating resistant bacteria. ${ }^{4,40}$

\section{HORMONAL AND OPTICAL THERAPIES}

Combined oral oestrogen and progesterone hormonal therapy is sometimes used as an adjunctive therapy for women with moderate to severe acne who also need oral contraception. ${ }^{4}$ Oestrogen helps to suppress sebaceous gland activity in addition to suppressing androgen synthesis; in contrast, progesterone, if used alone, can worsen acne. ${ }^{4}$ Optical treatments, particularly fractionated laser and photodynamic therapies, and selective photothermolysis can be useful in improving post-acne scarring; however, formal comparative studies have not yet been conducted. ${ }^{51,52}$ 


\section{CHALLENGES IN MANAGEMENT}

Additional challenges in management include determining the definitive timing of topical acne treatments and optimal management of post-acne scarring and hyperpigmentation as well as maintaining patient adherence to treatment..$^{53}$ The time taken between the initiation of topical therapy and clinicallyrelevant improvement is an important factor. In a systematic review on acne treatment, Jacobs et al. noted that different concentrations of BPO and adapalene did not seem to influence the time taken for resolution of inflammatory lesions; however, both agents produced earlier responses when compared to retinoids, particularly isotretinoin. ${ }^{54}$ In addition, combined clindamycin and BPO produced faster responses in comparison to adapalene alone. ${ }^{54}$ It is therefore necessary for clinicians to offer longerterm management plans in order to be sure that the treatments are successful in resolving the acne.

The management of acne in pregnant women is challenging largely due to the potential teratogenicity associated with retinoids, which considerably limits treatment options for patients with moderate to severe $a c n e .^{55,56}$ Women of childbearing age with acne should therefore be counselled and offered effective contraception before beginning treatment. Most specialists tend to use non-retinoid topical agents and add azelaic acid in an effort to improve efficacy and, more specifically, to help reduce the post-acneassociated hyperpigmentation.

\section{Conclusion}

Acne vulgaris is a chronic inflammatory disorder which occurs worldwide. Various effective and welltolerated options are available for the management of acne vulgaris, although none are optimal. For the management of mild to moderate acne, evidencebased guidelines advocate topical therapies, in particular BPO or adapalene, sometimes combined with antibiotics. Patients with severe acne can benefit from oral tretinoin; however, the drug is associated with potentially challenging side-effects. It is important for clinicians to recognise acne as a potentially serious medical condition and offer prompt management, appropriate counselling and support when indicated. The importance of a longer-term multi-disciplinary management plan in order to evoke a response to treatment should be emphasised. In addition, new clinical research is needed to assess the comparative effectiveness and safety of the many treatments available and the impact of patient compliance. Further research regarding the natural history, subtypes and triggers of acne is also required.

\section{ACKNOWLEDGEMENTS}

The Excellence in Dermatology Global InitiativE (EDGE) continuing medical education programme in Dubai was chaired by Anwar Al-Hammadi and included Sameer Al-Ali, Salah Al-Azawi, Hanish Babu, Vidya Kharkar, Lynn McKinley-Grant, Tariq Mughal and Mohammed Salah as faculty members. The EDGE continuing medical education programme in Muscat was chaired by Abla Al-Ismaily and included Fatima Al-Balushi, Abdullah Al-Taie, Damodar Bandodkar, Lynn McKinley-Grant and Tariq Mughal as faculty members. The authors would like to thank the Global WebRx team for their assistance with the programme logistics. In addition, the authors are grateful to Glenmark Pharmaceuticals Private Ltd., India, for funding the project.

\section{CONFLICT OF INTEREST}

Rajesh Ramadurai and Rishi Jain were employees of Glenmark Pharmaceuticals Private Ltd. until early 2016. The other authors declare no conflicts of interest.

\section{References}

1. Knutsen-Larson S, Dawson AL, Dunnick CA, Dellavalle RP Acne vulgaris: Pathogenesis, treatment, and needs assessment. Dermatol Clin 2012; 30:99-106. doi: 10.1016/j.det.2011.09.001.

2. Fisk WA, Lev-Tov HA, Sivamani RK. Epidemiology and management of acne in adult women. Curr Dermatol Rep 2014; 3:29-39. doi: 10.1007/s13671-014-0071-4.

3. Grant RN. The history of acne. Proc R Soc Med 1951; 44:647-52.

4. Williams HC, Dellavalle RP, Garner S. Acne vulgaris. Lancet 2012; 379:361-72. doi: 10.1016/S0140-6736(11)60321-8.

5. Aksu AE, Metintas S, Saracoglu ZN, Gurel G, Sabuncu I, Arikan I, et al. Acne: Prevalence and relationship with dietary habits in Eskisehir, Turkey. J Eur Acad Dermatol Venereol 2012; 26:1503-9. doi: 10.1111/j.1468-3083.2011.04329.x.

6. Veith WB, Silverberg NB. The association of acne vulgaris with diet. Cutis 2011; 8:84-91.

7. He L, Wu WJ, Yang JK, Cheng H, Zuo XB, Lai W, et al. Two new susceptibility loci 1q24.2 and 11p11.2 confer risk to severe acne. Nat Commun 2014; 5:2870. doi: 10.1038/ncomms3870.

8. Selway JL, Kurczab T, Kealey T, Langlands K. Toll-like receptor 2 activation and comedogenesis: Implications for the pathogenesis of acne. BMC Dermatol 2013; 13:10 doi: 10.1186/1471-5945-13-10.

9. Bhate $\mathrm{K}, \mathrm{W}$ illiams HC. What's new in acne? An analysis of systematic reviews published 2011-2012. Clin Exp Dermatol 2014; 39:273-7. doi: 10.1111/ced.12270.

10. Dawson AL, Dellavalle RP. Acne vulgaris. BMJ 2013; 346:f2634. doi: 10.1136/bmj.f2634.

11. Al-Mutairi N, Zaki A, Shiltawi M, Manchanda Y, Nouridin O, Sharma AK. Pattern of skin diseases in Farwaniya region in Kuwait. Gulf J Dermatol 2004; 11:5-13. 
12. Al Shobaili HA. The pattern of skin diseases in the Qassim region of Saudi Arabia: What the primary care physician should know. Ann Saudi Med 2010; 30:448-53. doi: 10.4103/0256 4947.72263 .

13. Al-Ameer AM, Al-Akloby OM. Demographic features and seasonal variations in patients with acne vulgaris in Saudi Arabia: A hospital-based study. Int J Dermatol 2002; 41:870-1. doi: 10.1046/j.1365-4362.2002.01669.x.

14. Al-Hammadi A. Personal communication, 2013.

15. Abu Shareeah AM. United Arab Emirates. In: Parish LC Millikan LE, Global Dermatology: Diagnosis and management according to geography, climate, and culture. New York, USA: Springer-Verlag, 1994. Pp. 301-5.

16. Abu Share'ah AM, Abdel Dayem H. The incidence of skin diseases in Abu Dhabi (United Arab Emirates). Int J Dermatol 1991; 30:121-4.

17. El-Essawi D, Musial JL, Hammad A, Lim HW. A survey of skin disease and skin-related issues in Arab Americans. J Am Acad Dermatol 2007; 56:933-8. doi: 10.1016/j.jaad.2007.01.031.

18. Ghodsi SZ, Orawa H, Zouboulis CC. Prevalence, severity, and severity risk factors of acne in high school pupils: A communitybased study. J Invest Dermatol 2009; 129:2136-41. doi: 10.1038/ jid.2009.47.

19. Ismail $\mathrm{KH}$, Mohmmed-Ali KB. Quality of life in patients with acne in Erbil city. Health Qual Life Outcomes 2012; 10:60. doi: 10.1186/1477-7525-10-60

20. Al-Kubaisy W, Abdullah NN, Kahn SM, Zia M Sociodemographic characteristics of acne among university students in Damascus, Syria. Epidemiol Res Int 2014. 2014:974019. doi: 10.1155/2014/974019.

21. Marples RR, Downing DT, Kligman AM. Control of free fatty acids in human surface lipids by Corynebacterium acnes. Invest Dermatol 1971; 56:127-31. doi: 10.1111/1523-1747. ep12260695.

22. Agak GW, Qin M, Nobe J, Kim MH, Krutzik SR, Tristan GR, et al. Propionibacterium acnes induces an IL-17 response in acne vulgaris that is regulated by vitamin A and vitamin D. J Invest Dermatol 2014; 134:366-73. doi: 10.1038/jid.2013.334.

23. Kistowska M, Gehrke S, Jankovic D, Kerl K, Fettelschoss A, Feldmeyer L, et al. IL-1 $\beta$ drives inflammatory responses to propionibacterium acnes in vitro and in vivo. J Invest Dermatol 2014; 134:677-85. doi: 10.1038/jid.2013.438.

24. Yaykasli KO, Turan H, Kaya E, Hatipoglu OF. Polymorphisms in the promoters of MMP-2 and TIMP-2 genes in patients with acne vulgaris. Int J Clin Exp Med 2013; 6:967-72.

25. Melnik BC, Schmitz G, Zouboulis CC. Anti-acne agents attenuates FGFR2 signal transduction in acne. J Invest Dermatol 2009; 129:1868-77. doi: 10.1038/jid.2009.8.

26. Benjamin LT, Trowers AB, Schachner LA. Successful acne treatment in Apert syndrome twins. Pediatr Dermatol 2005; 22:561-5. doi: 10.1111/j.1525-1470.2005.00141.x.

27. Belleudi F, Leone L, Nobili V, Raffa S, Francesganceli F, Maggio M, et al. Keratinocyte growth factor receptor ligands target the receptor to different intracellular pathways. Traffic 2007; 8:1854-72. doi: 10.1111/j.1600-0854.2007.00651.x.

28. Pu Y, Huang L, Birch L, Prins GS. Androgen regulation of prostate morphoregulatory gene expression: Fgf10-dependent and -independent pathways. Endocrinology 2007; 148:1697-706. doi: 10.1210/en.2006-1113.

29. Ozdemir M, Ozdemir G, Sasmaz S, Arican O. Ocular surface disorders and tear function changes in nodulo-cystic acne. J Dermatol 2005; 32:174-8. doi: 10.1111/j.1346-8138.2005. tb00740.x.

30. Silverberg JI, Silverberg NB. Epidemiology and extracutaneous comorbidities of severe acne in adolescence: A U.S. populationbased study. Br J Dermatol 2014; 170:1136-42. doi: 10.1111/ bjd.12912.
31. Al Mashat S, Al Sharif N, Zimmo S. Acne awareness and perception among population in Jeddah, Saudi Arabia. J Saudi Soc Dermatol Dermatol Surg 2013; 17:47-9. doi: 10.1016/j. jssdds.2013.05.003.

32. Golchai J, Khani SH, Heidarzadeh A, Eshkevari SS, Alizade N, Eftekhari $\mathrm{H}$. Comparison of anxiety and depression in patients with acne vulgaris and healthy individuals. Indian J Dermatol 2010; 55:352-4. doi: 10.4103/0019-5154.74539.

33. Gollnick HP. From new findings in acne pathogenesis to new approaches in treatment. J Eur Acad Dermatol Venereol 2015; 29:1-7. doi: $10.1111 /$ jdv.13186.

34. Al Ameer AM, Al Akioby OM, Al Omran IT. Acne scarring and its incidence in Saudi Arabia (A clinical evaluation study). Gulf J Dermatol 2003; 10:23.

35. Strauss JS, Krowchuk DP, Leyden JJ, Lucky AW, Shalita AR, Siegfried EC, et al. Guidelines of care for acne vulgaris management. J Am Acad Dermatol 2007; 56:651-63. doi: 10. 1016/j.jaad.2006.08.048.

36. Thiboutot DM, Weiss I, Bucko A, Eichenfield L, Jones T, Clark S, et al. Adapalene-benzoyl peroxide, a fixed-dose combination for the treatment of acne vulgaris: Results of a multicenter, randomized double-blind, controlled study. I Am Acad Dermatol 2007; 57:791-9. doi: 10.1016/j.jaad.2007.06.006.

37. Dréno B, Kaufmann R, Talarico S, Torres Lozada V, RodríguezCastellanos MA, Gómez-Flores M, et al. Combination therapy with adapalene-benzoyl peroxide and oral lymecycline in the treatment of moderate to severe acne vulgaris: A multicentre, randomized, double-blind controlled study. Br J Dermatol 2011; 165:383-90. doi: 10.1111/j.1365-2133.2011.10374.x.

38. Özgen ZY, Gürbüz O. A randomized, double-blind comparison of nadifloxacin $1 \%$ cream alone and with benzoyl peroxide $5 \%$ lotion in the treatment of mild to moderate facial acne vulgaris. Marmara Med J 2013; 26:17-20. doi: 10.5472/MMJ/2012.02649.

39. Poulin Y, Sanchez NP, Bucko A, Fowler J, Jarratt M, Kempers S, et al. A 6-month maintenance therapy with adapalene-benzoyl peroxide gel prevents relapse and continuously improves efficacy among patients with severe acne vulgaris: Results of a randomized controlled trial. Br J Dermatol 2011; 164:1376-82. doi: 10.1111/j.1365-2133.2011.10344.x.

40. Zaenglein AL, Thiboutot DM. Expert committee recommendations for acne management. Pediatrics 2006; 118:1188-99. doi: 10.1542/peds.2005-2022.

41. American Academy of Dermatology. Clinical guidelines. From: www.aad.org/practice-tools/quality-care/clinical-guidelines Accessed: Jan 2016.

42. Jones DH, King K, Miller AJ, Cunliffe WJ. A dose-response study of I3-cis-retinoic acid in acne vulgaris. Br J Dermatol 1983; 108:333-43. doi: 10.1111/j.1365-2133.1983.tb03973.x.

43. Gollnick HH, Cunliffe W, Berson D, Dreno B, Finlay A, Leyden JJ, et al. Management of acne: A report from a Global Alliance to Improve Outcomes in Acne. I Am Acad Dermatol 2003; 49:S1-37. doi: 10.1067/mjd.2003.618.

44. Bener A, Lestringant GG, Ehlayel MS, Saarinen K, Takiddin AH. Treatment outcome of acne vulgaris with oral isotretinoin. J Coll Physicians Surg Pak 2009; 19:49-51. doi: 01.2009/JCPSP. 4951.

45. Zane LT, Leyden WA, Marqueling AL, Manos MM. A population-based analysis of laboratory abnormalities during isotretinoin therapy for acne vulgaris. Arch Dermatol 2006; 142:1016-22. doi: 10.1001/archderm.142.8.1016.

46. Akman A, Durusoy C, Senturk M, Koc CK, Soyturk D, Alpsoy E. Treatment of acne with intermittent and conventional isotretinoin: A randomized, controlled multicenter study. Arch Dermatol Res 2007; 299:467-73. doi: 10.1007/s00403-0070777-2.

47. Amichai B, Shemer A, Grunwald MH. Low-dose isotretinoin in the treatment of acne vulgaris. J Am Acad Dermatol 2006; 54:644-6. doi: 10.1016/j.jaad.2005.11.1061 
48. Veltri KT. Acne pharmacotherapy: A review. U.S. Pharm 2013; 38:43-6.

49. Nakase K, Nakaminami H, Takenaka Y, Hayashi N, Kawashima M, Noguchi N. Relationship between the severity of acne vulgaris and antimicrobial resistance of bacteria isolated from acne lesions in a hospital in Japan. J Med Microbiol 2014. 63:721-8. doi: 10.1099/jmm.0.067611-0.

50. Luk NM, Hui M, Lee HC, Fu LH, Liu ZH, Lam LY, et al. Antibiotic-resistant Propionibacterium acnes among acne patients in a regional skin centre in Hong Kong. J Eur Acad Dermatol Venereol 2013; 27:31-6. doi: 10.1111/j.1468-3083. 2011.04351.x

51. Webster GF. Light and laser therapy for acne: Sham or science? Facts and controversies. Clin Dermatol 2010; 28:31-3. doi: 10.1016/j.clindermatol.2009.04.002

52. Paithankar D, Sakamoto FH, Farinelli WA, Kositratna G, Blomgren RD, Meyer TJ, et al. Acne treatment based on selective photothermolysis of sebaceous follicles with topically delivered light-absorbing gold microparticles. J Invest Dermatol 2015; 135:1727-34. doi: 10.1038/jid.2015.89.
53. Layton A, Eady EA, Peat M, Whitehouse H, Levell N, Ridd M, et al. Identifying acne treatment uncertainties via a James Lind Alliance Priority Setting Partnership. BMJ Open 2015; 5:e008085. doi: 10.1136/bmjopen-2015-008085.

54. Jacobs A, Starke G, Rosumeck S, Nast A. Systematic review on the rapidity of the onset of action of topical treatments in the therapy of mild-to-moderate acne vulgaris. Br J Dermatol 2014; 170:557-64. doi: 10.1111/bjd.12706.

55. Meredith FM, Ormerod AD. The management of acne vulgaris in pregnancy. Am J Clin Dermatol 2013; 14:351-8. doi: 10.1007/ s40257-013-0041-9.

56. Zouboulis CC, Bettoli V. Management of severe acne Br J Dermatol 2015; 172:27-36. doi: 10.1111/bjd.13639. 